\title{
Supplementary materials of : Slow drying of a spray of nanoparticle solution. In situ SAXS investigation
}

Debasis Sen ${ }^{1,2}$, Olivier Spalla ${ }^{1}$, Olivier Taché ${ }^{1}$, Patrick Haltebourg ${ }^{1}$, Antoine Thill ${ }^{1,3}$

January 18,2007

\footnotetext{
${ }^{1}$ CEA Saclay, Direction des Sciences de la Matière, Laboratoire Interdisciplinaire sur l'Organisation Nanométrique et Supramoléculaire, 91191 Gif-sur-Yvette, France

${ }^{2}$ Solid State Physics Division, Bhabha Atomic Research Center, Mumbai- 400 085, India

${ }^{3}$ corresponding author: antoine.thill@cea.fr
} 


\section{Full size SEM images}

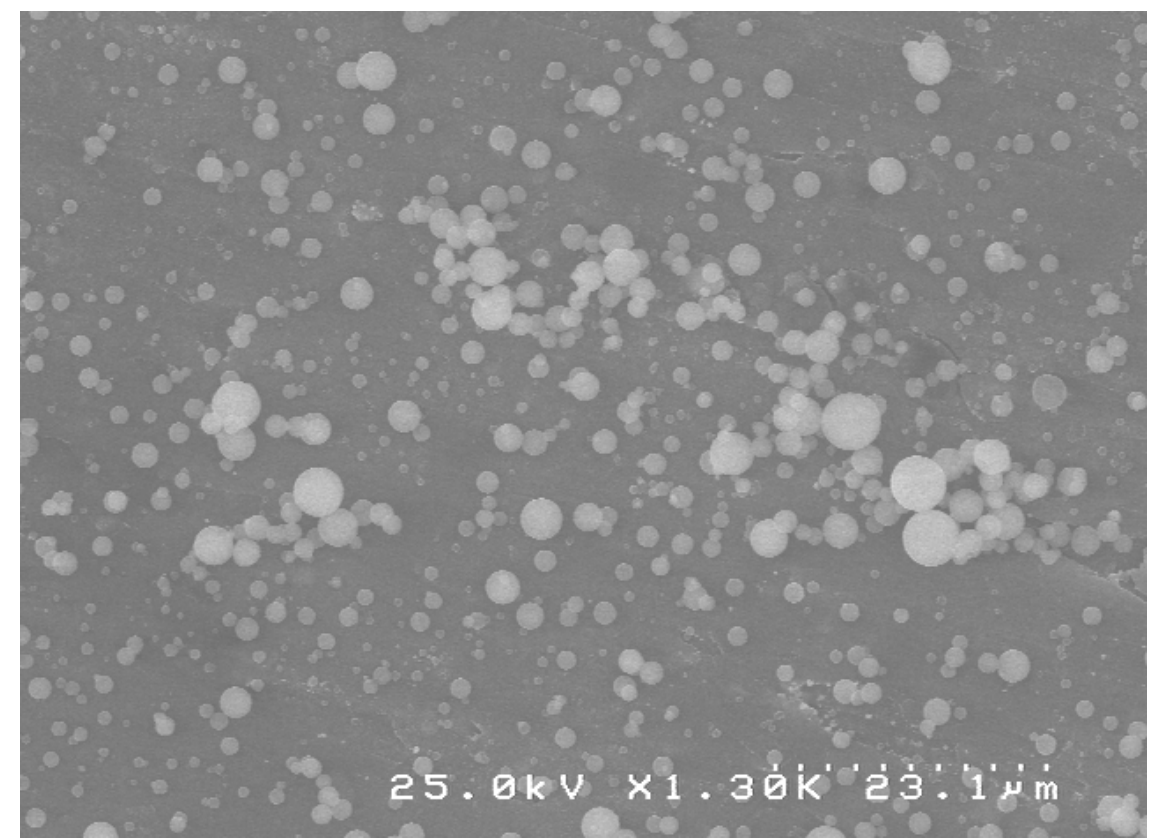

Figure 1: SEM micrographs of the final dry powder with oven heating zones bottom/middle/top set at respectively $200^{\circ} \mathrm{C} / 200^{\circ} \mathrm{C} / 200^{\circ} \mathrm{C}$ 


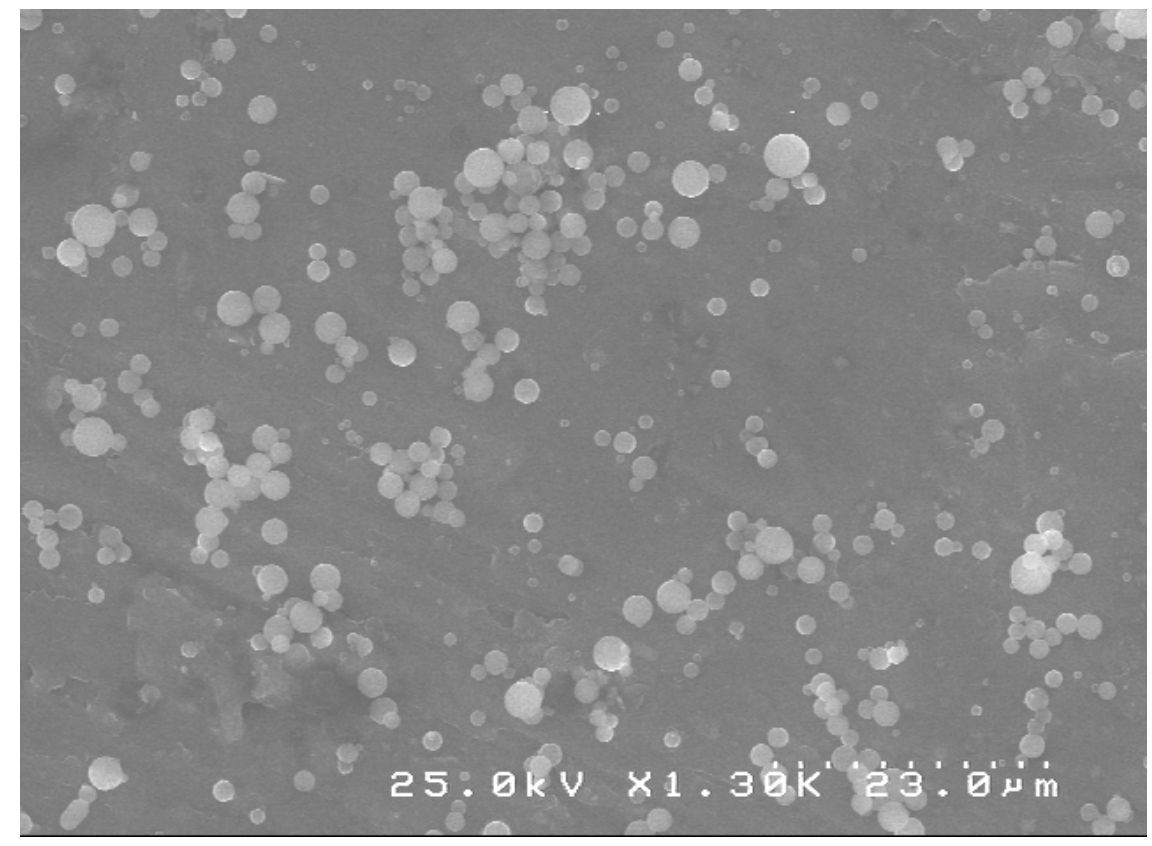

Figure 2: SEM micrographs of the final dry powder with oven heating zones bottom/middle/top set at respectively $200^{\circ} \mathrm{C} / 200^{\circ} \mathrm{C} / 200^{\circ} \mathrm{C}$ 


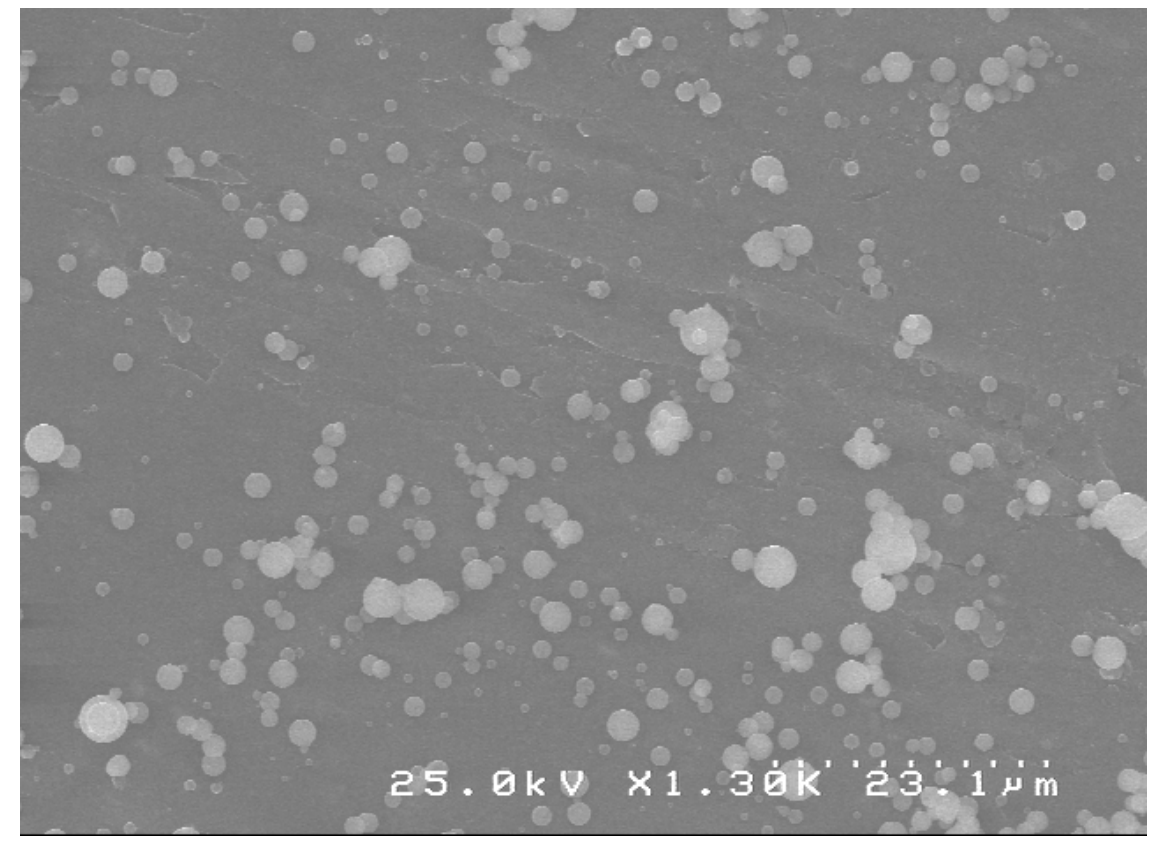

Figure 3: SEM micrographs of the final dry powder with oven heating zones bottom/middle/top set at respectively $150^{\circ} \mathrm{C} / 150^{\circ} \mathrm{C} / 150^{\circ} \mathrm{C}$ 


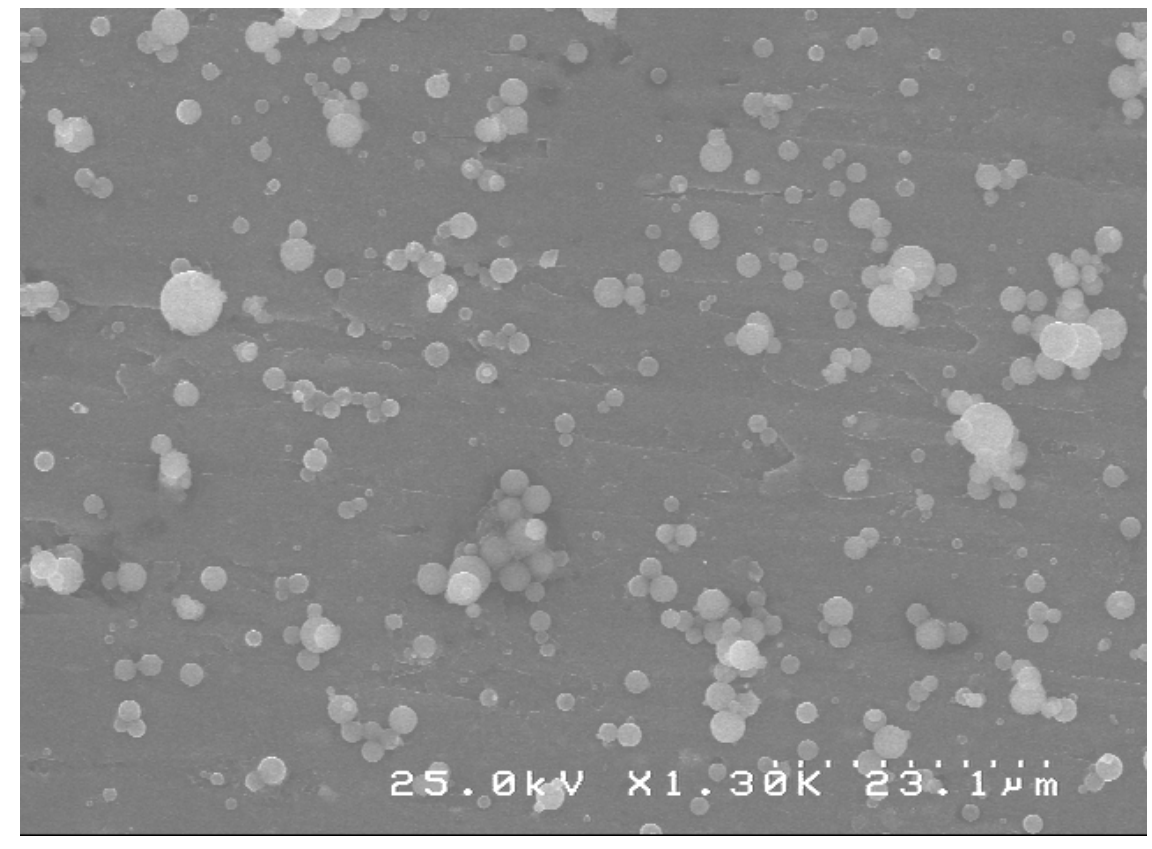

Figure 4: SEM micrographs of the final dry powder with oven heating zones bottom/middle/top set at respectively $150^{\circ} \mathrm{C} / 150^{\circ} \mathrm{C} / 150^{\circ} \mathrm{C}$ 